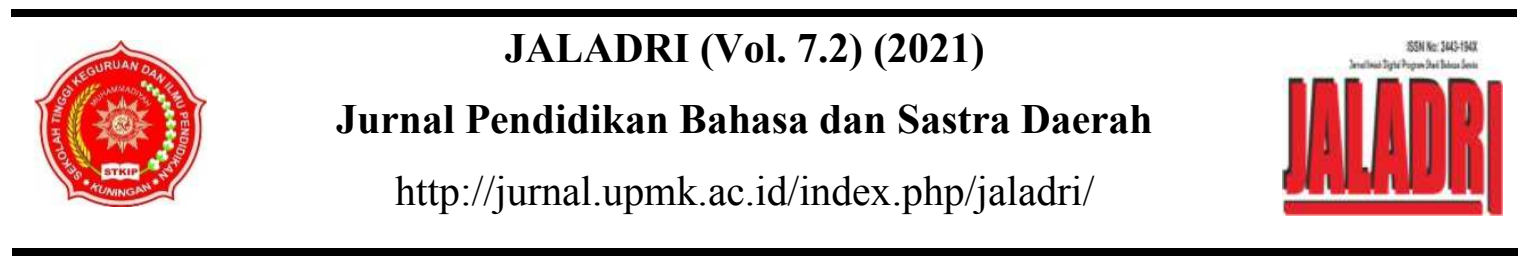

\title{
ANALISIS STRUKTUR DAN NILAI MORAL DALAM NOVEL SITI RAYATI KARYA MOH. SANOESI
}

\author{
Ratih Fauziah $^{1}$, Heti Triwahyuni ${ }^{2}$ \\ rtihfzh@gmail.com¹, triwahyuniheti@upmk.ac.id ${ }^{2}$ \\ ${ }^{1,2}$ STKIP Muhammadiyah Kuningan, Indonesia
}

\section{Info Artikel \\ Sejarah Artikel: \\ Diterima 25 September 2021 \\ Disetujui 6 Oktober 2021 \\ Dipublikasikan 25 Oktober 2021}

Kata Kunci:

nilai moral, novel, struktur

Key Words:

moral values,

novel, structure

\begin{abstract}
Abstrak
Latar belakang penelitian ini adalah rasa penarasan terhadap novel Siti Rayati karya Moh. Sanoesi yang direkomendasikan dinas Pendidikan, memiliki struktur unik juga mengandung moral kehidupan. Tujuan penelitian ini mendeskripsikan struktur dan nilai moral dalam novel tersebut. Penelitian ini menggunakan pendekatan struktur sastra. Metode yang digunakan yaitu metode deskriptif. Tehnik penelitian menggunakan studi pustaka dengan instrumen penelitian kartu data. Hasil penelitian, tema novel tersebut yaitu tema keluarga. Alur yang digunakan yakni alur maju. Latar tempat yang ditemukan ada 55 latar waktu, 53 latar tempat, dan 10 suasana. Pelaku novel ada 18 yang terbagi menjadi pelaku utama, kedua, dan tambahan. Nilai moral dalam novel ada 18, mencangkup 8 hubungan manusia terhadap diri pribadi, 4 hubungan manusia dengan manusia lain, dan 6 hubungan manusia kepada Sang Pencipta.
\end{abstract}

\section{Abstrack}

The background of this research is a sense of curiosity to the novel Siti Rayati by Moh. Sanoesi, which was recommended by the Education Office, has a unique story structure that also contains the moral values of life. The purpose of this study is to describe the structure and moral values in the novel Siti Rayati by Moh. Sanoesi. This study uses a literary structure approach. The method used is descriptive method which produces descriptive data. The research technique used is a literature study technique by looking for data according to research. The research instrument uses data cards. The results of the study, the structure of the novel's theme is the family theme. The flow used is the forward flow. There are 55 time settings, 53 place settings, and 10 atmosphere settings. There are 18 actors in Siti Rayati's novel which are divided into main, second, and additional actors. There are 18 moral values in the novel, covering 8 human relationships with oneself, 4 human relationships with other humans, and 6 human relationships with the Creator 


\section{PENDAHULUAN}

Dalam memahami sebuah cerita dalam karya sastra, pembaca harus paham mengenai struktur serta unsur yang terkandung dalam cerita, salah satunya yakni karya sastra novel. Menganalisis sebuah novel merupakan upaya untuk mendapatkan amanat serta ide penulis melalui pemahaman struktur dan nilai moral yang ada dalam karya tersebut. Struktur merupakan pengorganisasian unsur-unsur yang saling berkaitan satu sama lain dalam sebuah cerita yaitu novel. Karena itu, analisis truktur ditujukan untuk menjelaskan secara teliti dan rinci unsur satu dengan yang lainnya sehingga membentuk sebuah makna. Sesuai dengan pendapat Iskandarwassid (1996: 153), struktur adalah susunan komponen karangan yang menghasilkan wujud karya sastra dan mempunyai makna. Dalam prosa, struktur itu mencangkup unsur tema, plot, lata dan tokoh sehingga bisa mewujud sebuah karya cerita. Selain menganalisis struktur, dalam sebuah novel tentu mengandung nilai moral. Nilai moral yang ada dalam cerita merupakan gambaran dari kehidupan sehari-hari manusia, begitu juga dalam novel Sunda tentu saja nilai moral tersebut sudah menjadi tatakrama orang Sunda.

Nilai moral merupakan tingkah laku manusia yang baik dan yang buruk dalam kehidupan masyarakat. Contoh perilaku manusia yang baik adalah manusia yang memiliki etika dan sopan santun. Akan tetapi, seiring perkembangan jaman, nilai moral semakin lama mengalami perubahan. Perubahan tersebut bukan semakin baik, tapi nyatanya kini perubahan nilai moral malah semakin buruk. Contoh tidak menghormati orang yang lebih tua, serta ridak bisa menyesuaikan diri dengan lingkungan dan keadaan masyarakat sekitar. Bakar (Sufa, 2018: 1), nilai moral adalah nilai yang sangat penting dalam kehidupan khususnya bagi usia anak dan remaja agar mereka bisa membedakan mana yang baik dan mana yang buruk. Maka, masalah moral tidak bisa dipisahkan dalam kehidupan manusia. Nilai moral yang dapat diterapkan tentu ada dalam cerita maupun karya sastra salah satunya novel.

Novel merupakan karya sastra berupa cerita rekaan dalam bentuk tulisan dan mengandung unsur intrinsik juga ekstrinsik. Novel biasanya menceritakan kehidupan manusia yang berkaitan dengan lingkungan. Dalam sebuah novel, penulis menyampaikan idenya pada pembaca sesuai dengan kenyataan dalam kehidupan sehari-hari.

Berdasarkan pemaparan tadi, agar mengetahui struktur serta nila moral dalam sebuah novel, dipilih novel Siti Rayati karya Moh. Sanoesi. Novel ini dipilih karena mempunyai struktur cerita yang unik, banyak mengandung nilai moral dan yang terpenting novel ini sesuai dengan SK Kepala Dinas Pendidikan Jawa Barat karena menyarakan novel tersebut digunakan dalam pembelajaran di sekolah.

\section{METODE PENELITIAN}

Metode yang digunakan untuk menganalisis struktur dan nilai moral dalam novel ini yakni melalui metode deskriptif kualitatif. Metode deskriptif merupakan metode yang meneliti status kelompok manusia, satu subyek, susunan keadaan, sistem pemikiran serta kejadian dalam suatu waktu (Nazir dalam Sandy Fajar, Sumiyadi, 2018: 1783). Penggunaan metode deskriptif bertujuan agar hasil penelitian ini mendapatkan data yang diolah menjadi deskripsi dan gambaran secara sistematis terkait hubungan antara fenomena yang diteliti.

Jenis penelitian menggunakan jenis kualitatif. Menurut Moloeng (Rostiyati et al., 2019: 40), penelitian kualitatif adalah 
penelitian untuk memahami fenomena yang dialami oleh subyek penelitian. Jenis penelitian kualitatif hasilnya berupa kata, gambar dan bentuknya bukan berupa angka (Moleong dalam Elisabet Saina, Syamsiyah, 2020: 9). Sumber data yang digunakan dalam penelitian ini adalah data yang berasal dari kertas atau dokumen (paper). Menurut Arikunto (Nurhasyanah \& Ropiah, 2018: 10), sumber data penelitian merupakan subyek dari mana berasalnya sebuah data. Agar lebih mudah mengidentifikasi data, maka data tersebut diklasifikasikan dalam tiga bagian yaitu person, place, dan paper.

Teknik yang digunakan dalam mengumpulkan data data penelitian adalah teknik studi pustaka. Teknik studi pustaka merupakan teknik untuk mendapatkan beberapa teori yang dijadikan acuan dalam melaksanakan penelitian melalui sebuah instrumen yakni kartu data (Suyatna dalam Nurhasyanah \& Ropiah, 2018: 10). Analisis data yang digunakan dalam penelitian ini yakni analisis struktur serta nilai moral yang ada pada novel Siti Rayati karya Moh. Sanoesi. Data yang sudah terkumpul kemudian dianalisis. Menurut Arikunto (Nurasiah, 2017: 32), analisis data mencangkup tiga ha yaitu persiapan, tabulasi dan memanfaatkan data sesuai pendekatan dalam penelitian. Tahap persiapan adalah kegiatan dari mulai melaksanakan kegiatan penelitian. Tabulasi yaitu menyatukan datadata yang ditemukan, kemudian tahap selanjutnya data tersebut diolah sesuai dengan struktur dan nilai moral yang terkandung dalam novel Siti Rayati karya Moh. Sanoesi.

\section{HASIL DAN PEMBAHASAN}

\section{Analisis Struktur}

Novel yang digunakan dalam penelitian ini yaitu novel Siti Rayati karya Moh. Sanoesi, tebalnya 75 halaman dengan ukuran
$20,9 \mathrm{~cm}$ x 14,6 cm diterbitkan oleh PT. Kiblat

Buku Utama, cetakan kedua tahun 2020.

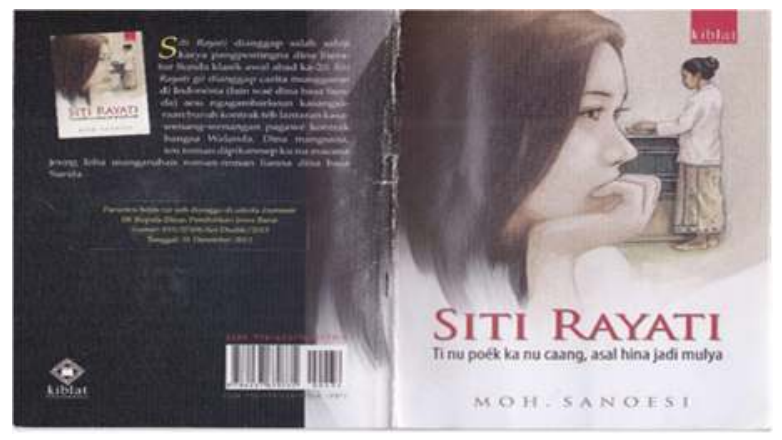

Gambar 1. Novel Siti Rayati karya

Moh. Sanoesi

Hasil penelitian analisis struktur dalam novél Siti Rayati berdasarkan teori Iskandarwassid yang mencangkup tema, alur, latar, dan pelaku. Teori struktur yang pertama yaitu tema. Tema dalam novel Siti Rayati yaitu tema mengenai keluarga. Novel ini menggambarkan kehidupan seorang manusia bernama Siti Rayati dari mulai bayi hingga ia bertemu dengan sososk ibu aslinya. Tema tersebut dapat dilihat pada kutipan:

Isukna Pangawulaan teu damangna beuki maju, sarta kawasna anjeunna geus béda raraosan, tuluy sabot euweuh garwana, sasauran ka putrana, "Ti, ayeuna rék nyarita, tapi Titi sing tawekal, ulah rék reuwasreuwas, ieu Mama geus béda rarasaan, Mama boga rasiah, anu ayeuna rék dibéjakeun ka Titi, Titi téh saenyana anak kukutan...." Di dieu Gan Titi ngagebeg, reup geuneuk ray pias, ngadangu ramana nu sasauranana geus harésé semu nu eungap. (SR/68)

Dari kutipan diatas, ayah Siti Rayati sedang dalam keadaan sakit. Ia pun akhirnya menceritakan bahwa sebenaranya Siti Rayati bukanlah anak asli. Selanjutnya struktur yang kedua 
yaitu alur cerita. Alur dalam novel Siti Rayati adalah alur maju, karena jalan ceritanya tidak balik ke masa lampau melainkan maju dari mulai Siti Rayati saat masih kecil hingga dewasa.

"Éh, Nyai anaking...," cék indungna, bari cipanon rambay, nyampingan anakna $k u$ sarung bawana téa; tuluy dilahun disusuan, "ayeuna ku Ema Nyai dipasrahkeun deui $k a \quad n u$ kagungan... ka Nu Kawasa... ka nu ngalahirkeun Nyai ka dunya... Ku Ema ayeuna Nyai ditinggalkeun... sabab Ema moal kuat.... moal iklas nénjo Nyai dibabawa balangsak... dibabawa sangsara ku Ema... Atuh, aya baé umur Nyai jeung umur Ema... milik Nyai jeung milik Ema... diparengkeun ku Nu Kawasa bisa patepung deui... éta nu ku Ema disuhunkeun ka Nu Agung... nu diteteda beurang peuting ka Pangéran.. Nyai muga-muga Nu Kawasa maparin ka diri Nyai karahmatan jeung kasalametan... muga-muga Nyai sing datang ka dampal leungeun jelema anu alus jeung luhur budina... Nyai... Nyai Ema indit... Aduuuuuuh tobat, Pangéran,... tobat, abdi dosa...." (SR/35)

Supaya sakabéh terang, Gan Titi terusna nikah, jeung jurnalis tukang ngarang, salamet aya berekah. Tina damelna kaluar, terus angkat $k a$ Semarang, ngadamel di surat kabar, jadi pembantu pangarang. Ibuna, Patimah téa, ku anjeunna disirnakeun, Si Nani raina téa, dicandak disakolakeun. Ma Lurah ti Cirayati, kitu deui salakina, dipikolot ku Gan Titi, diurus taya kendatna. Gan Titi jeung salakina, éstu euweuh kuciwana, duanana nyepeng péna, nyerat ngabéla rayatna. $(S R / 74-75)$

Kutipan diatas menunjukkan Siti Rayati saat dilahirkan dan pada akhirnya, Siti Rayati menikah dengan jurnalis dan pindah ke Semarang bersama suaminya. Bahkan, adik tirinya Nani kini disekolahkan dan Siti rayati juga suaminaya aktif bekerja di surat kabar.

Struktur selanjutnya adalah latar. Latar yang terdapat dalan Novel Siti Rayati karya Moh. Sanoesi terbagi menjadi 3 yakni laatr waktu, latar tempat dan latar suasana. Latar waktu terdapat 55 frekuensi yang terbagi lagi menjadi latar bulan, hari dan jam dalam Sunda. Contoh kutipan latar waktu yaitu:

BULAN April, poé Saptu, kirakira pukul lima soré, rabul awéwé-lalaki, kolot-budak ka palasar kontrakan Ragasirna, ngabalanjakeun duitna, duit ladang késangna buburuh di éta kontrakan. (SR/7)

Kutipan tersebut menunjukkan latar waktu bulan yang menjelaskan bahwa pada bulan April hari Sabtu masarakat yang menempati Ragasirna melakukan kegiatan berbelanja dari hasil buruh payah di ladang. Latar kedua yakni latar tempat terdapat 53 frekuensi, terbagi mejadi 2 ada latar umum serta latar khusus. Latar umum menunjukkan tempat sosial, artinya tempat tersebut digunakan secara umum oleh masyarakat contohnya Pasar kontrakan Ragasirna, kontrakan Ragasirna, kebun, dijalan, pabrik, pinggir jalan, lembur Sindangpalay, warung nasi, Desa Cirayati, saung di kebun nanas, distrik Pakemitan, Frobelschool, dsb. Contoh kutipan latar tempat yaitu: 
Beuki ka sareupnakeun beuki juljol jelema daratang, sarta ayeuna mah lain bujang-bujangna atawa kuli-kulina di éta kontrakan baé, tapi ogé ti kontrakan-kontrakan jeung ti lembur-lembur séjén anu deukeut ka kontrakan Ragasirna, daratang maruru lalajo wayang golék, anu heuleut saminggu dihaja diayakeun di pasar $k u$ kawasana éta kontrakan. (SR/7)

Latar khusus yaitu latar yang menunjukkan tempat secara khusus atau spesifik. Latar khusus dalam novel Siti Rayati yaitu rumah Tuan Steenhart, halaman rumah Tuan Steenhart, kamar Tuan Steenhart, rumah Patimah, kamar, dapur rumah Patimah, ruang tengah rumah Patimah, gudang, gedung Tuan Kawasa, rumah paraji, rumah Ambu Armi, dapur rumah Ambu Armi, dll.

Babu tukang nyeuseuh di Tuan van der Goud ayeuna dicandak ngalih ku Gan Titi, sarta dibayar saperti baréto, malah salakina ogé ayeuna mah meutingna sok di bumi anjeunna baé ngabaturan. $(S R / 60)$

Dari kutipan tersebut, pembantu tukang cuci dan suaminya dibawa pindah ke rumah Siti Rayati serta dibayar seperti dulu mereka ketika bekerja di Tuan van der Goud. Latar yang ketiga yaitu latar suasana. Latar suasana novel Siti Rayati banyak mengandung suasana kesedihan dan diakhir cerita mengandung suasana bahagia. Pelaku Patimah mengalami suasana yang sedih karena ia diperkosa sampai mengandung. Bahkan anak kandung tersebut tidak diakui oleh ayahnya. Patimah memutuskan muntuk melahirkan anaknya dikebun nanas dan pergi dari kontrakan Ragasirna agar tidak ada yang tahu keberadaan tentang kehamilannya.

Si Babu ngomong kénéh, gabrug ku Gan Titi jeung sémah téa dirontok, inget, cocog jeung katerangan pamajikan Lurah Cirayati, pagulung-gulung jeung sémah, anu ayeuna ngarti, yakin yén babu, Patimah téa, ibuna tulén Gan Siti Rayati, anu ramana Tuan Steenhart, anu ayeuna geus euweuh di kieuna.....

"Hapunten Ibu... hapunten... tobat ampun... nya abdi putra Ibu téh... abdi... abdi...," saur Gan Titi ka ibuna, kadéngé sorana ngalengis, suka pabaur jeung duka, asih pacampur jeung sedih! (SR/74)

Dari kutipan diatas, Siti Rayati akhirnya tahu bahwa babu Patimah adalah ibu kandungnya serta ayahnya adalah Tuan Steenhart, yang sudah meninggal akibat perilaku yang tidak baik.

Unsur berikutnya adalah unsur pelaku. Pelaku dalam novel Siti Rayati ada 18, yaitu Siti Rayati, Patimah, Tuan Steenhart, Jaya, Juragan Mandor Sastra, Ma Sarminah, Nyonya Tuan Kawasa, Ambu Armi, Tukang kebon Tuan Kawasa, Ma Sarinten, Tukang Warung, Juragan Wadana, Nyai Radén Siti Winangsih, Natamanggala Lurah Cirayati, Nyi Lurah Cirayati, Juffrouw, Dr. Van Der Groud, dan Nyonya Van Der Groud. Berdasarkan pelakunya masingmasing, pelaku tersebut dibagi menjadi 3 ada pelaku utama, pelaku kedua dan pelaku tambahan.

Pelaku utama dalam novel Siti Rayati adalah pelaku yang ada dari mulai awal sampai akhir cerita. Selain itu, pelaku utama mempunyai ciri sering muncul dan jadi pusat cerita. 
pemberani

Siti Rayati - Pintar, baik, dan

Unggal taun Gan Titi naék, tur kaasup murid nu pangmajuna; nya barang kaluar ogé ti éta sakola, jadi yuswa tilu welas taun, jol-jol meunang baé samenna $\mathrm{ka}$ sakola HBS téh, malah dina surat kabar ogé di antara bangsa Walanda anu mareunang, jenengan anjeunna kasebut nomer dua. $(S R / 40)$

Palaku selanjutnya yakni pelaku kedua. Pelaku kedua adalah pelaku yang membantu atau menjadi lawan pelaku utama. Dalam novel ini, yang menjadi pelaku kedua ada 3, yaitu Patimah, Tuan Steenhart dan Juragan Wadana.

penurut

Patimah - Rajin bekerja dan

"Parantos sasasih," wangsulna si

awéwé bari tungkul, jongjon metik. $(S R / 13)$

"Nyai cing ka ditu ka Nyonya Tuan Kawasa, nyuhunkeun daun buntiris keur ubar cangkéng," cék Ma Sarminah ka anakna.

"Sing loba, Ma?"

"Sakeupeul baé Nyai," wangsulna bari pupurilitan ngurutan cangkéngna. (SR/24-25)

Dari kutipan diatas, pelaku Patimah ditanya oleh seseorang bernama Tuan Steenhart sambil memetik teh. Selain itu, ibunya Patimah menyuruhnya untuk meminta daun obat sakit pinggang.

Tuan Steenhart - Kasar

Kalakuanana Tuan Steenhart anu sarupa kitu, geus henteu matak kagét deui pikeun urang kontrakan Ragasirna mah, beunang disebutkeun kajadian kitu téh unggal poé, nyarékan atawa neunggeulan, nyiksa jelema anu teu pira kasalahanana. $(S R / 12)$

Pelaku Tuan Steenhart digambarkan sebagai sosok yang suka marah, ringan tangan, dan mudah sekali menyakiti orang lain yang tidak punya salah.

Juragan Wadana - Tegas

"Ti," saur anjeunna, "Mama téh nu matak gancang datang ka dieu, barang Mama maca surat kitu ti Titi. Ayeuna mah terus terang baé ka Mama meureun Titi téh henteu betah reureu jeungan jeung Embina, nya? Tah ayeuna mah béjakeun baé ku Titi ka Mama, naon kateungeunah téh atawa sok kumaha Embi téh?" (SR/55)

Kutipan tersebut menunjukkan Ayah Siti Rayati yang bertanya atas kepergian anaknya meninggalkan Kabupaten karena tidak betah tinggal bersama ibu tirinya.

Ketiga ada pelaku tambahan atau pelaku yang tidak terlalu penting dalam sebuah cerita. Pelaku tambahan dalam novel Siti Rayati karya Moh. Sanoesi terdapat 14 pelaku yaitu Jaya, Juragan Mandor Sastra, Ma Sarminah, Nyonya Tuan Kawasa, Ambu Armi, Tukang kebon Tuan Kawasa, Ma Sarinten, Tukang Warung, Nyai Radén Siti Winangsih, Natamanggala Lurah Cirayati, Nyi Lurah Cirayati, Juffrouw, Dr. Van Der Groud, dan Nyonya Van Der Groud. Pelaku tambahan dalam dilihat dalam kutipan berikut:

$$
\begin{aligned}
& \text { Jaya - Penurut } \\
& \text { "Jaya!" manéhna nyalukan } \\
& \text { jongosna, "coba juragan minta } \\
& \text { bréndi én bawa dus sigarét." }
\end{aligned}
$$


"Bréndi sareng plésna baé juragan?" (SR/8)

Kutipan tersebut menunjukkan pelaku tambahan bernama Jaya sangat mematuhi perintah Tuannya yakni Tuan Steenhart agar membelikannya minuman alkohol beserta rokok 1 dus.

\section{dan baik}

Juragan Mandor Sastra - Penurut

Meunang saminggu manéhna henteu kaluar-luar tapi ari duit mah jeung kahakanan heunteu petot dianteuran baé ku Mandor Sastra, titahan Tuan Steenhart. (SR/18)

Pok mandor ngomong sakumaha nu geus dibadamikeun tadi di imah, sarta caritaanana diatur dilelemu, dilelewang, sangkan dununganana welaseun jeung asiheun ka Patimah. (SR/31)

Pelaku bernama Juragan Mandor Sastra sering menjadi pesuruh Tuan Steenhart agar memberikan uang dan makanan kepada Patimah. Tak hanya itu, dalam kutipan selanjutnya, Juragan Mnador Sastra mau membantu Patimah sebagai perantara kepada Tuan Steenhart.

Ma Sarminah - Baik

$\mathrm{Ku}$ sabab éta indungna ogé kapaksa henteu ka pabrik, teu iklaseun ninggalkeun anakna anu ngan sahiji-hijina tur gering. (SR/17)

Kutipan tersebut menunjukkan Ibunya Patimah sangat baik sebab merelakan pergi ke pabrik karena anaknya yang sedang sakit.

Nyonya Tuan Kawasa - Baik

"Ya, ya boléh hoor, ambil saja!" $(S R / 25)$
Nyonya Tuan Kawasa sebgai pelaku tambahan memiliki hati yang baik sebab memberikan ijin kepada Patimah untuk mengambil daun burintis obat sakit pinggang Ibunya.

\section{Ambu Armi - Peduli \\ Ti harita sanggeus indungna maot, manéhna ti dinya pindah, sarta terus nganjrek di Ambu Armi, pamajikan tukang kebon Tuan Kawasa. (SR/25-26)}

Kutipan sebelumnya menunjukkan bahwa saat Patimah ditinggal mati Ibunya, Ambu Armi yang mau memberikan tempat tinggal untuk Patimah.

Peduli

Tukang kebon Tuan Kawasa -

"Geura saré Nyai ka dituh, ku naon nu susah, bisi gering," cék salakina Ambu Armi bari indit ka ngahuleng baé kawas enggonna, "Kadé engké poho, ari rék saré seuneu céos heula." (SR/28)

Pelaku tambahan yakni suami Ambu Armi memberikan perhatian layaknya seorang ayah pada anaknya yakni Patima agar tidur lebih awal.

Ma Sarinten - Perhatian

"Ieuh kieu ayeuna mah, Ema méré naséhat, kaharti ku Ema ogé, atuh da Ema asalna ngora. Tapi ayeuna kieu, Nyai indit isuk pagéto ka nu nyieun, ka nu boga dosa, ka bapana budak ménta dikawin, moal enya teu daékeun, sieuneun atuh didakwa..." (SR/26)

Ma Sarinten memberikan perhatian kepada Patimah agar pergi meminta dinikahi pada ayah dari si jabang bayi. 
Tukang Warung - Peduli

"Di dieu baé Nyai entong terus, ari kesel-kesel mah tuh ngamesin. Gampang ari geus salamet mah, masing rék ka mana-mana ogé pék baé. Geura kumaha lamun engké ngajuru di tengah-tengah jalan. Sarta sanajan salamet ogé nepi ka Sukabumi, leuheung basa lamun aya kénéh sadérék, kumaha lamun teu nyampak?" (SR/33)

Kutipan di atas menunjukkan saat pelaku Patimah sedang kesusahan akibat mengandung, ia diberikan tempat tinggal oleh Ibu tukang warung.

Nyai Radén Siti Winangsih - Baik Budak ku juragan istri dicandak ka jero bumi, sarta tuluy dimandian ku anjeun. "Engkang $k a$ dieu heula sakedap," saur anjeunna, "ituh tingali, curukna méh baé sapat, ku naon nya?" (SR/38)

Pelaku bernama Nyai Radén Siti Winangsih adalah sosok yang baik sebab sosok bayi yang ditemukan di kebun nanas ia rawat layaknya anak sendiri.

Baik

Natamanggala Lurah Cirayati -

"Ari parantos ... kumaha atuh da geuning teu beunang dipikahayang... Aéh itu Engkang... saha... geura... aya awéwé ngais budak diiringkeun ku Lurah?" (SR/37)

"Sumuhun dawuh," wangsulna, "jisim abdi téh nyanggakeun bebendu baé, réhna kamari kinten tabuh salapan énjing-énjing, pun bojo ka kebon badé ngala ganas, sanggakeuneun ka Gamparan. Nanging dongkap ka saung, di kebon, pun bojo mendak ieu orok, dituruban ku ranggap." (SR/37)

Lurah Cirayati sebagai pelaku tambahan adalah sosok yang baik karena mau mengantarkan serta menyelamatkan bayi yang ditemukannya di kebun nans kepada Juragan Wadana.

Nyi Lurah Cirayati - Baik

Derekdek pamajikan Natamanggala nyarita ti awal nepi ka ahir, kumaha asal-asalna Gan Titi panggih di kebon ganas, dikurungan ku ranggap, nepi ka terus disalabarkeun tapi euweuh nu ngaku, sarta tungtungna $k u$ manéhna disanggakeun $k a$ ramana keur waktu jeneng kénéh Wadana di Pakemitan, nya nepi ka ayeuna. (SR/70)

Kutipan diatas, menunjukkan istri Natamanggala yang menceritakan saat menemukan dan menyelamatkan Siti Rayati. Ia menemukan bayi yang dicari keberadaan orang tuanya namun tak kunjung temu.

Juffrouw - Baik
Guruna juffrouw kacida pisan
nyaaheunana ka Gan Titi,
lantaran ku tina calakanana sarta
wanter, loba anak bangsa
Walanda nu kaéléhkeun ku
anjeunna, boh dina ngomong boh
dina sagala rupa kaulinan atawa
karajinan budak leutik. (SR/40)

Guruna Siti Rayati bernama Juffrouw sangat menyayangi Siti Rayati karena ia pintar dan juga pemberani. Tak hanya itu Juffrouw sangat bangga karena muridnya terampil dalam permainan kanak-kanak.

Dr. Van Der Groud - Baik 
Nya henteu lila ti harita sanggeus Gan Titi nampi waleran ti ramana yén taya halangananana, anjeunna tuluy baé ngalih $k a$ Batawi, calik di Dr. van der Goud Salémba. (SR/41)

Kutipan tersebut menunjukkan bahwa Siti Rayati diberikan tempat tinggal sementara oleh Dr. Van Der Goud Salémba.

\section{Nyonya Van Der Groud - Pengertian}

"Hadé ogé manéhna maca buku anu kitu malah manéhna hiji urang Pribumi, urang Hindia, perlu nyaho kaayaan nu sarupa kitu, ngan... ngan risi ogé... lantaran ayeuna manéhna keur diajar kénéh. Dilarang ku aing, tangtu manéhna tambah panasaran, tambah hayangna nyaho..." (SR/43)

Kutipan diatas, Nyonya Van Der Groud memberikan pengertian kepada Siti Rayati yang hanya orang Pribumi namun ia membaca buku karya asing diusia yang belia.

\section{Nilai Moral}

Wujud nilai moral dalam novel Siti Rayati dibagi berdasarkan tingkah laku manusia dalam menjalani sebuah kehidupan. Wujud nilai moral tersebut yaitu nilai moral hubungan manusia terhadap dirinya, hubungan manusia dengan manusia lain (lingkup sosial atau lingkungan alam), dan hubungan manusia kepada Sang Pencipta.

1. Hubungan manusia terhadap dirinya

Hubungan manusia terhadap dirinya merupakan bentuk nilai moral manusai yang memperlakukan hal baik terhadap dirinya sendiri. Nilai moral sendiri memiliki tujuan agara manusia tersebut bisa menjadi pribadi yang lebih baik, juga dapat membedakan mana yang baik dan buruk. Nilai moral hubungan manusia terhadap dirinya ada 8 dalam novel Siti Rayati karya Moh. Sanoesi, salah satunya dapat dilihat sebagai berikut:

a) Tanggung jawab

Tanggung jawab adalah kesadaran manusia terhadap apa yang sudah dilakukan baik maupun buruk.

Pagétona, Pangawulaan jeung putrana marulih, sarta ti harita Gan Titi nu kudu bebenah petapeta di Kabupatén téh narima tamu; péndékna sagala pagawéan $n u$ tadina dicepeng $k u$ ibuna ayeuna mah kabéh ku Gan Titi baé. (SR/46)

Kutipan tersebut menggambarkan nilai tanggung jawab berupa pekerjaan alamh. Ibu Siti Rayati yang harus beralih tanggung jawab oleh anaknya.

b) Hidup realistis

Menerima kenyataan hidup merupakan nilai moral diri pribadi yang menerima kenyataan yang sedang dijalani.

"Ti, Mama ayeuna rék nyarita, tapi Titi sing tawekal, ulah rék reuwas-reuwas, ieu Mama geus béda rarasaan, Mama boga rasiah, anu ayeuna rék dibéjakeun ka Titi, Titi téh saenyana anak kukutan...." (SR/68)

Kutipan tersebut menggambarkan Siti Rayati yang harus menerima 
kenyataan bahwa sebenarnya ia hanyalah anak pungut dari Juragan Wadana.

c) Teguh pendirian

Kehidupan tokoh Siti Rayati digambarkan sebagai pribadi yang kuat dan tidak terpengaruh oleh pendapat oran lain.

Pangawulaan anu sakitu didesek ku putrana, henteu weléh sasauran, ngalelemu Gan Titi, sangkan teu tulus kagungan carogé ka jurnalis NN tapi percuma baé, da sakecap ogé euweuh nu asup. (SR/66)

Siti Rayati teguh pendirian terhadap keputusannya, dan tidak tergoyahkan atas kemauan tokoh maupun orang lain.

2. Hubungan manusia dengan manusia lain

$\begin{array}{lr}\text { Hubungan manusia dengan } \\ \text { manusia lain berkaitan } & \text { dengan } \\ \text { permasalahan kehidupan antar manusia }\end{array}$ dalam satu lingkungan. Permasalahn tersebut bisa negatif atau positif. Nilai moral hubungan manusia dengan manusia lain dalam novel Siti Rayati ada 4 contoh kutipannya yaitu:

a) Perilaku baik antar sesama

Nilai moral tersebut berkaitan dengan keikhlasan terhadap orang lain, rasa mau berbagi dan menolong sesama.

"Karunya, dagoan heula Bu, kuring méré!" saur Gan Titi bari lumpat ka jero nyandak raksukan lungsuran. (SR/53)

Kutipan tersebut menggambarkan keikhlasan Siti Ryati menolong sesama dengan menberikan sebagian bajunya pada seorang Ibu.

b) Empati dan solidaritas terhadap orang lain
Rasa empati artinya keinginan manusia untuk memahami keadaan hidup manusia lainnya. Selain itu dengan adanyarasa empati manusia bisa saling mwerasakan apa yang tengah dialami oleh manusia tersebut.

"Alah, Nyai, sakitu sabrolbroleun étah geuning... entong, Nya, di dieu baé di Ema... Entong mikir naon-naon... keun baé da sakopeun baé mah aya...," cék tukang warung, bari ngulangngulang hoé, ngagebahan laleur anu ngagembrong kana kahakanan. "Di dieu baé Nyai entong terus, ari kesel-kesel mah tuh ngamesin. Gampang ari geus salamet mah, masing rék ka manamana ogé pék baé. Geura kumaha lamun engké ngajuru di tengahtengah jalan. Sarta sanajan salamet ogé nepi ka Sukabumi, leuheung basa lamun aya kénéh sadérék, kumaha lamun teu nyampak?" (SR/33)

Dari kutipan tersebut menunjukkan rasa empati Tukang warung pada Patimah yang sedang kesusahan ditambah ia sedang mengandung.

c) Berbaik sangka

Bentuk nilai moral manusia dengan manusai lainnya adalah berbaik sangka. Berbaik sangka adalah wujud hati nurani yang baik.

"Enya, Nyai, entong asa-asa, hiap ka dieu," sarta Patimah tuluy ditungtun ku nu boga warung, diperenahkeun dina hiji pangkéng. (SR/34)

Kutipan diatas, menggambarkan Tukang Warung yang tidak berprasangka buruk terhadap sosok Patimah. 
3. Hubungan manusia kepada Sang Pencipta

Hubungan manusia kepada Sang Pencipta dalam kehidupan sehari-hari yakni sebagai tempat mengadu, berlindung dan meminta pertolongan. Hubungan manusia kepada Sang Pencipta dalam novel Siti Rayati ada 8, salah satunya sebagai berikut:

a) Syukur kepada Allah

Dalam kehidupan, rasa syukur kepada Allah bisa dilakukan dengan ucapan atau tingkah laku. Rasa syukur memiliki arti berterima kasih atas permasalahan yang dihadapi.

Si Babu ngomong kénéh, gabrug ku Gan Titi jeung sémah téa dirontok, inget, cocog jeung katerangan pamajikan Lurah Cirayati, pagulung-gulung jeung sémah, anu ayeuna ngarti, yakin yén babu, Patimah téa, ibuna tulén Gan Siti Rayati, anu ramana Tuan Steenhart, anu ayeuna geus euweuh di kieuna.... (SR/74)

Sikap pelaku Siti Rayati sangat bahagia karena ia memuji kepada Sang Pencipta sebab akhirnya ia tahu bahwa ibu kandungnya adalah Patimah.

b) Percaya kepada Allah

Percaya kepada Allah merupakan bentuk mangrupa iman manusia kepada Sang Pencipta. Artinya manusia yakin akan kekuasaan Allah.

"Éh, Nyai anaking...," cék indungna, bari cipanon rambay, nyampingan anakna $k u$ sarung bawana téa; tuluy dilahun disusuan, “ayeuna ku Ema Nyai dipasrahkeun deui $k a \quad n u$ kagungan... ka Nu Kawasa... ka nu ngalahirkeun Nyai ka dunya... Ku Ema ayeuna Nyai ditinggalkeun... sabab Ema moal kuat.... moal iklas nénjo Nyai dibabawa balangsak... dibabawa sangsara ku Ema... Atuh, aya baé umur Nyai jeung umur Ema... milik Nyai jeung milik Ema... diparengkeun ku Nu Kawasa bisa patepung deui... éta nu ku Ema disuhunkeun ka Nu Agung... nu diteteda beurang peuting ka Pangéran.. Nyai muga-muga $\mathrm{Nu}$ Kawasa maparin ka diri Nyai karahmatan jeung kasalametan... muga-muga Nyai sing datang $k a$ dampal leungeun jelema anu alus jeung luhur budina... Nyai... Nyai Ema indit... Aduuuuun tobat, Pangéran,... tobat, abdi dosa...." (SR/35)

Patimah percaya bahwa Allah mempunyai kekuasaan, dan ia berserah diri pada yang maha kuasa atas perilakunya yang menyimpan bayinya di kebun nanas.

c) Melaksanakan perintah-Nya dan menjauhi larangan-Nya

Melaksanakan perintah-Nya dan menjauhi larangan-Nya adalah kewajiban yang harus dilakukan oleh seluruh umat umat manusia. Dasarnya kewajiban adalah hal yang harus dilakukan. Sedangkan larangan adalah perintah (aturan) yang melarang untuk melakukan perbuatan tersebut

Mimiti mah Si Patimah cicing baé, malah teu malik-malik acan, tungkul baé metik, haténa bingung mikiran éta duit nu diasong-asong ka hareupeunana bari mikir, ditampa kumaha, teu ditampa kumaha, sok sieun aya balukarna anu bakal margahala deui kana dirina. $(S R / 19)$

Patimah digambarkan dalam kutipan tersebut tidak mau melakukan perbuatan yang 
terlarang, sebab ia takut menerima balasan yang tidak baik bagi dirinya.

\section{KESIMPULAN}

Struktur novel Siti Rayati karya Moh. Sanoesi berdasarkan teori Iskandarwassid, yakni tema, alur, latar, dan pelaku. Tema novel yaitu tentang keluarga. Menceritakan pelaku yang bernama Siti Rayati, dari mulai ia kecil sampai ia menemukan ibu kandungnya. Alur dalam novel tersebut adalah alur maju karena menceritakan kehidupan pelaku utama dari mulai lahir hingga menjadi manusia dewasa. Latar dalam novel ini terdiri dari 55 latar waktu, 51 latar tempat, dan 10 latar suasana. Pelakunya terdapat 18 pelaku, yaitu Siti Rayati, Patimah, Tuan Steenhart, Juragan Wadana, Jaya, Juragan Mandor Sastra, Ma Sarminah, Nyonya Tuan Kawasa, Ambu Armi, Tukang kebon Tuan Kawasa, Ma Sarinten, Tukang Warung, Nyai Radén Siti Winangsih, Natamanggala Lurah Cirayati, Nyi Lurah Cirayati, Juffrouw, Dr. Van Der Groud, dan Nyonya Van Der Groud.

Sedangkan nilai moral dalam novel Siti Rayati karya Moh. Sanoesi ditemukan melalui sikap, tingkah laku, dan kalimat yang diucapkan pelaku. Menurut teori Nurgiyantoro, dibagi menjadi hubungan manusia dengan dirinya, hubungan manusia dengan manusia lain, serta hubungan manusia kepada Sang Pencipta. Nilai moral hubungan manusa terhadap dirinya ada 8 , hubungan manusia dengan manusia lain ada 4, dan hubungan manusia kepada Sang Pencipta ada 6.

\section{REFERENSI}

Iskandarwassid. (1996). Kamus Istilah Sastra Pangdeudeul Pangajaran Sastra Sunda (2 ed.). CV Geger Sunten.
Nurasiah, I. (2017). Struktur jeung Ajén Moral dina Novél Surat Wasiat Karangan Samsoedi pikeun Bahan Pangajaran Apresiasi Sastra di SMP.

Nurhasyanah, I., \& Ropiah, O. (2018). Analisis Struktural Jeung Ajén Moral dina Novél Kembang Asih Di Pasantrén Karya Edyana Latief. JALADRI (Jurnal Pendidikan Bahasa dan Sastra Daerah), 4(1), 118.

Rostiyati, Khuzaemah, E., \& Mulyaningsih, I. (2019). Analisis Nilai Moral Pada Buku Buya Hamka Sebuah Novel Biografi Karya Haidar Musyafa. Jurnal Bindo Sastra, 3(1), 39-47.

Sandy Fajar, Sumiyadi, E. K. (2018). Analisis Struktural jeung Nilai Moral Cerita Pendek Pilihan Surat Kabar Republika 2018. Seminar Internasional Riksa Bahasa XII, 1781-1790.

Sufa, R. F. (2018). Pesan Moral Dalam Novel Anak Rantau Karya a . Fuadi Dan Kemungkinan Sebagai Dengan Menggunakan Pendekatan Struktural. 